\title{
Dikey bahçe tasarımın estetik ve işlevsel boyutu: KTÜ Kanuni Kampüs
}

\section{Aesthetic and functional dimension of vertical garden design: KTU Kanuni Campus}

\author{
Elif BAYRAMOĞLU ${ }^{1}$ Makbulenur BEKAR ${ }^{1}$ (D) Banu Çiçek KURDOĞLU ${ }^{1}$
}

${ }^{1}$ Karadeniz Teknik Üniversitesi, Peyzaj Mimarlığı Bölümü, Trabzon

Eser Bilgisi / Article Info

Araştırma makalesi / Research article

DOI: 1017474/artvinofd.685227

Sorumlu yazar / Corresponding author

Elif BAYRAMOĞLU

e-mail: elifsol@hotmail.com

Geliş tarihi / Received

17.02.2020

Düzeltme tarihi / Received in revised form

21.04.2020

Kabul Tarihi / Accepted

07.05.2020

Elektronik erişim / Online available

01.09.2020

Anahtar kelimeler:

Sürdürülebilir tasarım

Peyzaj mimarlığı

Dikey bahçeler

Formal eğitim

\section{Keywords:}

Sustainable design

Landscape architecture

Vertical gardens

Formal education

\begin{abstract}
Özet
Dünya genelinde kentleşme oranı gittikçe artmakta ve 2050'ye kadar bu rakamın daha yüksek oranlara ulaşacağı ön görülmektedir. Dünyayı yaşanır hale getiren doğa ise, bu süreçten kötü etkilenmekte ve yeşil alan oranı gün geçtikçe azalmaktadır. Günümüzde bu problemleri düzeltmek için alınan önlemler genel tanımı ile "sürdürülebilir yaklaşım" başlığı altında toplanmaktadır. Yağmur bahçeleri, dikey bahçeler, çatı bahçeleri bu çalışmaların sadece bazılarıdır. Bu çalışmalar peyzaj mimarlığı meslek disiplinin de odak noktasında yerini almaktadır. Bu nedenle gerek formal gerekse informal eğitim sürecinde sürdürülebilirlik çalışmalarını yerini almaktadır. Öğrencilerin eğitim süreci içerisinde bu gibi kavramlar ile çalışmaları mezun olduklarında uygulamalarında daha fazla yermesine neden olmaktadır. Bu da 4 yılık eğitim süreçlerinin sonunda "farkındalık" etkisi yaratmaktadır. Yapılan bu çalışma, Karadeniz Teknik Üniversitesi Peyzaj Mimarlığı Bölümü Mühendislik Bilgisi dersi kapsamında "yeşil duvar olması önerilen bir duvarın" 2 haftalık ders süreci içerisinde tasarlanması ve ortaya çıkan ürünlerin peyzaj değeri açısından incelenmesini içermektedir. Çalışma sonucunda öncelikle tasarlanan duvarların peyzaj değeri açısından önemi ve ekolojik kaygılar ile yapılan tasarımların eğitim sürecindeki önemi vurgulanmıştır.
\end{abstract}

\begin{abstract}
The rate of urbanization is increasing all over the world and it is foreseen that this number will reach higher rates by 2050. The nature that makes the world livable is badly affected by this process and the rate of green area is decreasing day by day. Today, the measures taken to correct these problems are gathered under the title of sustainable approach in general definition. Rain gardens, vertical gardens, roof gardens are just some of these works. These studies take place in the focal point of the professional discipline of landscape architecture. Therefore, it replaces sustainability studies in both formal and informal education processes. Students' studies with such concepts in the education process cause them to have more place in their applications when they graduate. This creates an "awareness" effect at the end of 4-year training processes. Within the scope of this study, within the scope of the engineering knowledge course of the department of landscape architecture of Karadeniz Technical University, "a wall that is supposed to be a green wall is designed within a 3-month education period and the resulting products are examined in terms of landscape value. As a result of the study, the importance of the designed walls in terms of landscape value and the importance of the designs made with ecological concerns in the education process were emphasized.
\end{abstract}

\section{GiRiş}

Günümüzde kentleşmenin, nüfus artışının ve dolayısıyla iklim değişikliğinin sebep olduğu olumsuzlukları azaltmak ve daha sağlıklı bir dünyada yaşayabilmek için başta kentsel bölgeler olmak üzere gelişmekte olan yeni alanlarda ve kırsal alanlarda sürdürülebilir çalışmalara ağırlık verilmektedir (Ünal ve Akyüz 2018). Sürdürülebilir çalışmaların başında gelen yeşil altyapı planlamasının amaçları; mevcut yeşil alanları değerlendirmek ve kaybınıtahribini önlemek, yeşil alanların kalitesini ve çeşitliliğini arttırmak, stratejik bağlamda yaklaşarak yeşil alanları birbiriyle bağlantılı kılmak ve kent içerisinde tüm yeşil alanları dikkate almak olarak söylenebilir (Hepcan ve Hepcan, 2018). Yeşil altyapı uygulamaları ve sürdürülebilir yaklaşımlar nüfus artışının sebep olduğu yoğun kentleşme ve iklim değişikliğinin etkisini azaltma gibi önemli faydalarından dolayı dünyada yaygın şekilde kullanılmaktadır (Ünal ve Akyüz 2018). Yeşil çatı ve duvarların küresel ısınma etkisini etkilediği, kente birçok açıdan katkı sağladığını söylemektedir (Korol ve ar. 2019, Coma ve ark. 2017, Ragheb ve ark. 2016). Düşey duvarlar mimari öğelerde de yerini almaktadır. En genel tanımı ile bu yapılar "sürdürülebilir mimari" kavramının altında gelişmiştir. Bu yapıların tasarımında ekolojik bakış açısının 
katkısı günümüz tasarım eğitiminde vurgulanmalıdır (Güleç ve ark. 2015).

Duvarların vejetatif biçim almış durumları olan yeşil duvarlar sürdürülebilir yaklaşımlar arasında yerini almaktadır (Gren Roof Organization 2008). Bir başka tanımlama ise yeşil duvarlar, dikey olarak sınırlandırılmış bir alanın üzerine yayılan dikilmiş bitki örtüsüdür. Yapıların çatılarının ve duvarlarının bitkilendirilmesiyle, yapının adeta bitki ile kaplanması nedeniyle, bu sistemlere dikey bahçeler de denmektedir (Yüksel 2013). Bu duvarlar sadece estetik özellikleri ile değil aynı zamanda ortamı canlandırmaya yardımcı olmaktadır (Timur ve Karaca 2013).

Sonradan yapılan yapay öğelerden ve duvarlardan oluşan kentsel dokuların yoğun sert zeminli ortamlardan daha doğal, yumuşak, estetik, sağlıklı, yaşayan, yaşamsal değer taşımayan ve nefes alabilen, ekolojik mekanlara dönüşmeleri açısından dünyada dikey bahçe uygulamalarına önem verilmektedir. Dikey bahçe çalışmalarının yaygınlaşmasında; gerekli uygulamaların ve standartların yapılması, yerel yönetimlerin konuya olan duyarlııkları oldukça önemlidir (Bekar ve Güneroğlu 2016).

Bu çalışma kapsamında Karadeniz teknik üniversitesi peyzaj mimarlığı bölümü mühendislik bilgisi dersi kapsamında "yeşil duvar olması öngörülen bir duvarın" 2 hafta toplam $(4+4)$ ders saati içerisinde tasarlatılması istenmiş ve ortaya çıkan tasarım ürünleri peyzaj değeri açısından incelenmiştir. Bu süreç içerisinde ders kapsamında hedeflenen amaçlar şu şekilde sıralanmıştır;

- Öğrencilere ekolojik yaklaşımın gerekliliği ve önemini anlatabilmek,

- Öğrencilere, tasarladıkları duvarın kendi kullanım alanları içerisinde olması nedeniyle, çözümünün kendilerini etkileyeceği bir sorunu yerinde görerek çözmeye çalıştıkları bir tasarım süreci deneyimleme fırsatı sunmak

- Öğrencilerin ekolojik kaygılar ile tasarlama ve düşünme yeteneklerini arttırabilmek,
-Öğrencilerin ileride iş hayatlarında sürdürülebilir yaklaşımlara önem vermeleri konusunda farkındalıklarını arttırabilmek.

\section{MATERYAL ve YÖNTEM}

Çalışma Karadeniz Teknik Üniversitesi (Trabzon) Kanuni Kampüs sınırları 84 içerisinde gerçekleştirilmiştir. Çalışma 4 aşamadan oluşmaktadır (Şekil 1). Çalışmanın ilk aşamasını ders kapsamında yapılan teorik kısım oluşturmaktadır. íkinci kısımda ise uzman grubun problemli olarak gördüğü duvarın seçimi gerçekleştirilmiştir. Bu seçim için öncelikli olarak alanında uzman 30 peyzaj mimarına; "Karadeniz Teknik Üniversitesi Kanuni Kampüsü'nde düşey bahçe olarak değerlendirilebilecek 5 duvarı yazınız" sorusu sorulmuştur (Çizelge 1). Elde edilen veriler doğrultusunda Karadeniz Teknik Üniversitesi Tıp Fakültesi yolu üzerinde bulunan Şekil 1'deki duvar en çok tercih edilmiştir. Bu seçim işleminden sonra yöntemin 3. aşamasına geçilmiştir. Çalışmanın ikinci aşamasını seçilen bu duvarın (Çizelge 1) öğrenciler tarafından düşey bahçe olarak tasarım çalışmaları Karadeniz Teknik Üniversitesi Peyzaj Mimarlığı Bölümü 3. Sınıf öğrencilerinin Mühendislik Bilgisi dersinde gerçekleştirilmiştir. Konsept ve tasarım dengesi içerisinde yapmak istediklerini en iyi ifade eden 10 örnek seçilmiş ve çalışma kapsamında incelenmiştir (Çizelge 2). Çalışmanın son aşamasını ise 100 kişiye yapılan anket uygulaması oluşturmaktadır. Anketlerde seçilen 10 örneğin peyzaj değeri ve temel tasar öğeleri açısından sorgulanması yapılmıştır. Sorgulama işleminde 5 'li likert tutum skalası kullanıımıştır. 17 peyzaj değerin ifade eden sıfatlar 17 soruya çevrilmiş ve anket oluşturulmuştur. Anket çalışmasına, faktör analizi ve korelasyon testi uygulanmıştır. Faktör analizinde, 17 parametrenin en belirgin olanlarının ortaya çıkartılması hedeflenirken, korelasyon testi ile bu parametreler aralarındaki ilişki ölçülmüştür. Faktör analizi ile en etkili ilk bileşenler bulunmuş ve analiz gerçekleştirilmiştir (Çizelge 5). Faktör analizi Varimax rotasyonu kullanılmıştır. Analiz yapılırken parametreler başlıklara ayrılmıştır. Bu başlıklar; "estetik parametreler", "fonksiyonel parametreler" ve "bitkisel parametreler" olmak üzere gruplandırılmıştır. Analiz bu başlıklara dair en belirgin parametrelerin ortaya çıkmasında yardımcı olmuştur. 5 grup altında toplanan bu 
parametreler faktör analizi ile birbiriyle ilişkili olan ifadeleri ortaya çıkarmıştır. Böylece yeni faktör grupları ortaya çıkmıştır. Ankette, Likert tutum skalasında 1 en düşük oranı ifade ederken 5 en yüksek oranı ifade etmektedir. Anket verilerine dair sonuçlar Çizelge 1-3-45-6-8'de verilmiştir.

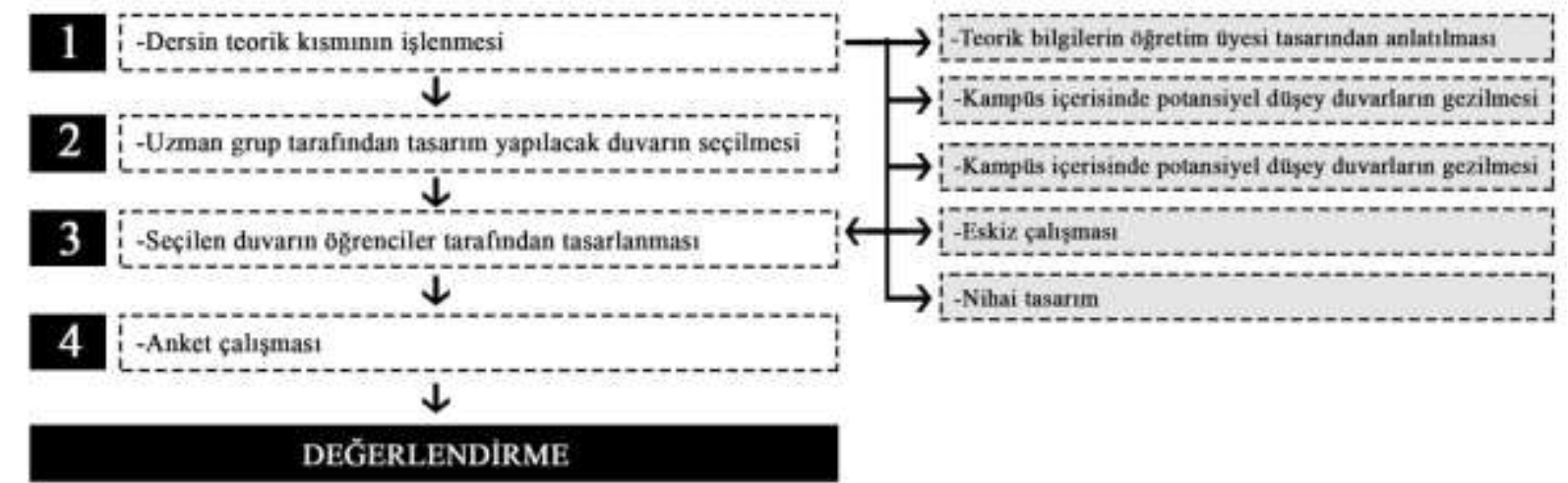

Şekil 1. Çalışma yöntem aşamaları

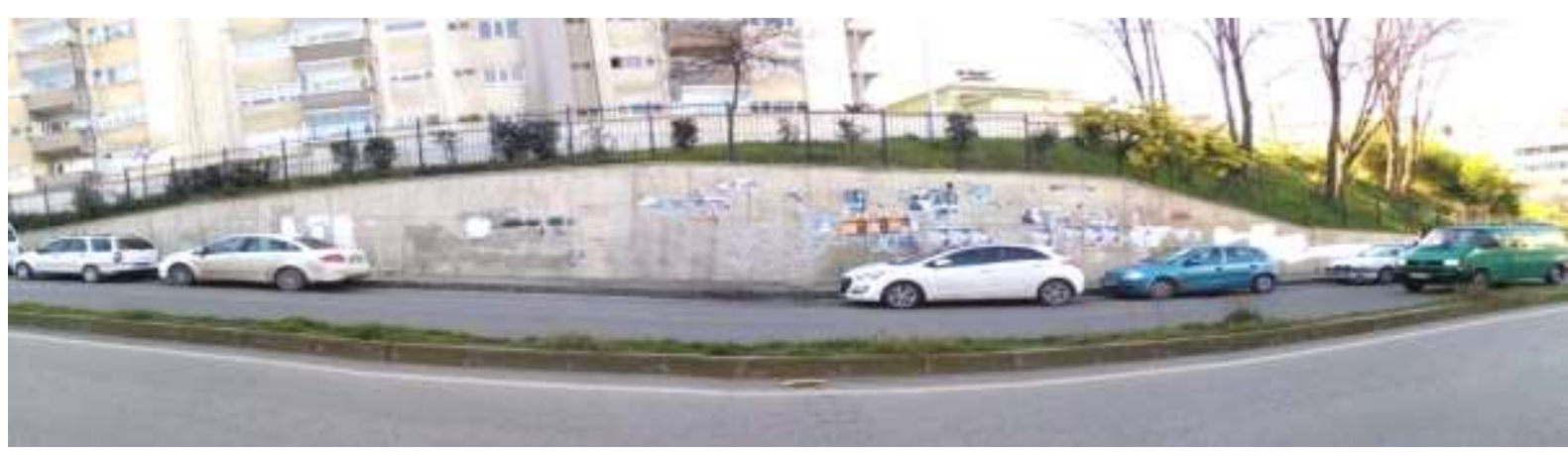

Şekil 2. Uzman grup tarafından belirlenen duvar

\section{BULGULAR}

Çalışma kapsamında uygulanan yöntem 4 aşamadan oluşmaktadır (Şekil 1). Yöntem bölümünde belirtildiği gibi öncelikli olarak kampüs içerisinde uzman grup tarafından düşey bahçe olarak tasarlanması öngörülen duvar seçilmiştir (Şekil 2). Uzman gruba 5 seçenekli şekilde duvarlar önerilmiş ve içlerinden "tıp fakültesi yol üzerindeki duvar" \%56.6 oranla en yüksek sonucu elde edilmiştir (Çizelge 1). Seçilen bu duvar öğrenciler tarafından tasarlanmış ve konuyu en iyi temsil eden 10 örnek seçilmiştir (Çizelge 2). Bu kapsamda her öğrenci kendine göre bir konsept seçmiş, konsepte dair karakter birliği örnekleri bulmuştur. Örnekler soyutlanmış ve nihai tasarımlar elde edilmiştir (Çizelge 2).

Çizelge 1. Uzman grubun soruya dair yanıtları

\begin{tabular}{|c|c|c|c|}
\hline \multicolumn{4}{|c|}{ Karadeniz Teknik Üniversitesi kanuni kampüsünde düşey duvar olarak değerlendirilebilecek 5 duvarı yazınız } \\
\hline Siralama & Saptanan Problemli Duvar & Frekans & Yüzde (\%) \\
\hline 1 & Tıp fakültesi yol üzerindeki duvar & 17 & 56.6 \\
\hline 2 & Maden mühendisliği arkasındaki duvar & 7 & 23.3 \\
\hline 3 & Orman endüstri mühendisliği arkasındaki duvar & 2 & 6.0 \\
\hline 4 & Öğrenci işlerinin arkasındaki duvar & 3 & 30 \\
\hline 5 & E kapısı yol boyunca ilerleyen duvar & 1 & 3,3 \\
\hline & Toplam & 30 & 100 \\
\hline
\end{tabular}


Çizelge 2. 10 öğrenciye dair çizim ve konsept detayları

Konsept Bilgileri
1.Konsept: Örümcek ağı
Örümcek ağındaki kırık yapı bir araya gelerek bitki
parsellerini oluşturmuştur.
2.Konsept: Su Damlacıkları
Su damlacıklarının yuvarlak formları iç içe girerek bitki
parsellerini oluşturmuştur.
3.Konsept: Devinim
Üçgen şeklindeki bitki parselleri birbirlerini arasında ölçü
farkları ile devinim etkisi yaratmaktadır.

\section{Konsept: Doğadaki düzen}

Doğadanın özünde var olan düzen etkisi bitki parsellerine yansımıştır. Bu yansıma çizgisel olarak ifade edilmiştir.

\section{Konsept: Dinginlik}

Dingin ve yumuşak geçişli bir etki yaratabilmek için organik formlu çizgiler kullanılmıştır.

\section{Konsept: Bal peteği}

Bal peteğinin doğal ve eşsiz dokusu oluşturabilmek için kullanılmıştır.

7.Konsept: Deniz esintisi

Dalgaların kıvrımları soyutlanarak bitki parselleri oluşturulmuştur.

\section{Konsept: Doğadaki enerji}

Enerji yapılacak olan formu ölçü, biçim ve organizasyon açısından etkilemiştir.

\section{Konsept: Doğadaki ritim}

Bitki parsellerini oluşturan form birbirileri arasında bir ritim duygusu oluşturmaktadır

10.Konsept: Doğal çizgiler

Doğanın organik formları elipslere dönüştürülerek bitki parselleri oluşturulmuştur.
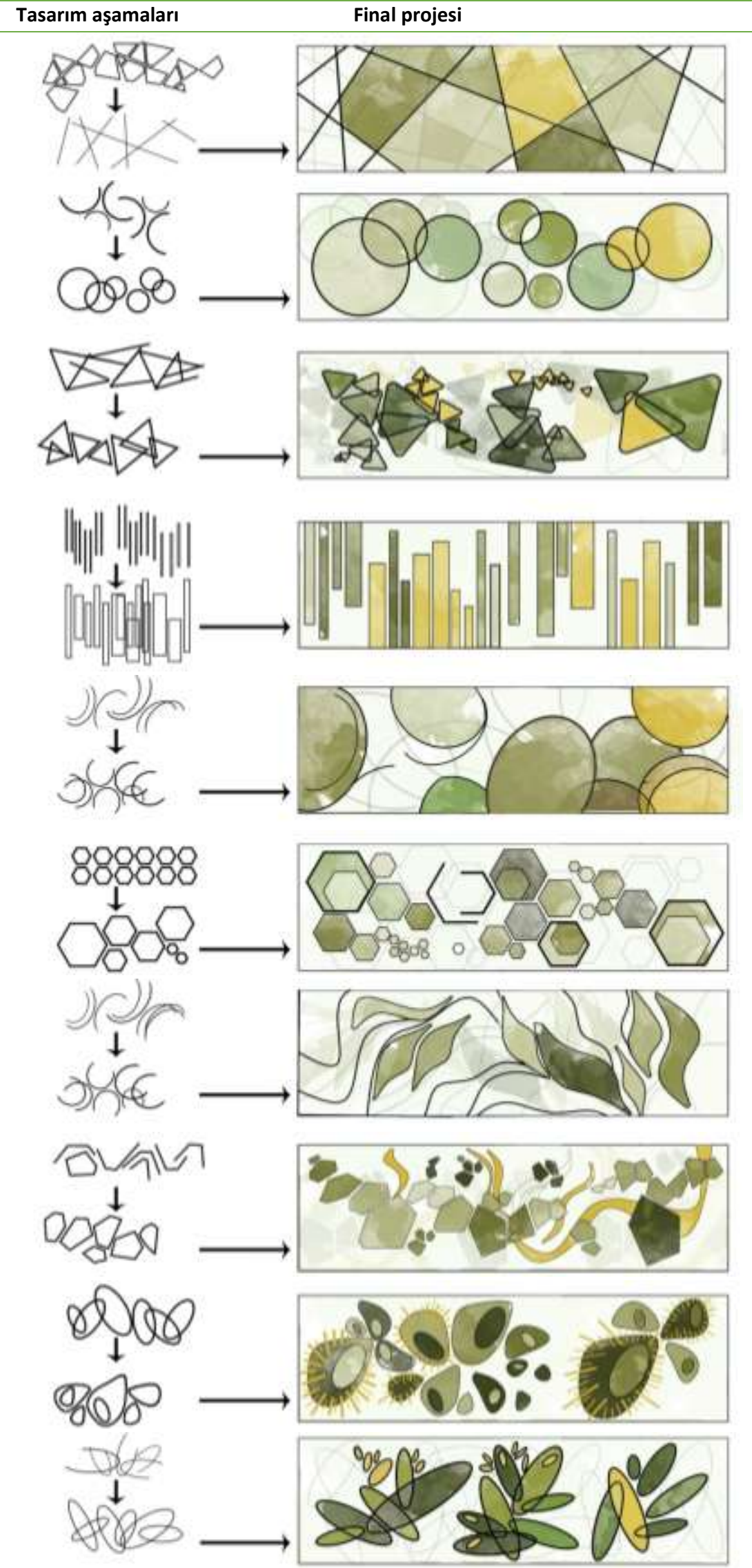
Çalışmanın bundan sonraki aşamasında istatistik analizler (faktör analizi ve korelasyon testleri) uygulanmıştır. Çizilen 10 tasarım yapılan anket çalışması ile puanlatılmıştır (Çizelge 3-4). 100 kişiden oluşan katılımcılardan tasarımları +1 ve +5 arasında puanlamaları istenmiştir. En yüksek puanı 7 numaralı tasarım almıştır (Çizelge 3-4).

Çizelge 3. Tasarımların puan skalası

\begin{tabular}{cc}
\hline Projeler & Aldı̆̆ puan \\
\hline 1 no'lu proje & +257 \\
2 no'lu proje & +230 \\
3 no'lu proje & +129 \\
4 no'lu proje & +389 \\
5 no'lu proje & +267 \\
6 no'lu proje & +400 \\
7 no'lu proje & +458 \\
8 no'lu proje & +287 \\
9 no'lu proje & +348 \\
\hline 10 no'lu proje & +368 \\
\hline
\end{tabular}

Çizelge 4. Tasarımın duvardaki uygulanmış durumu

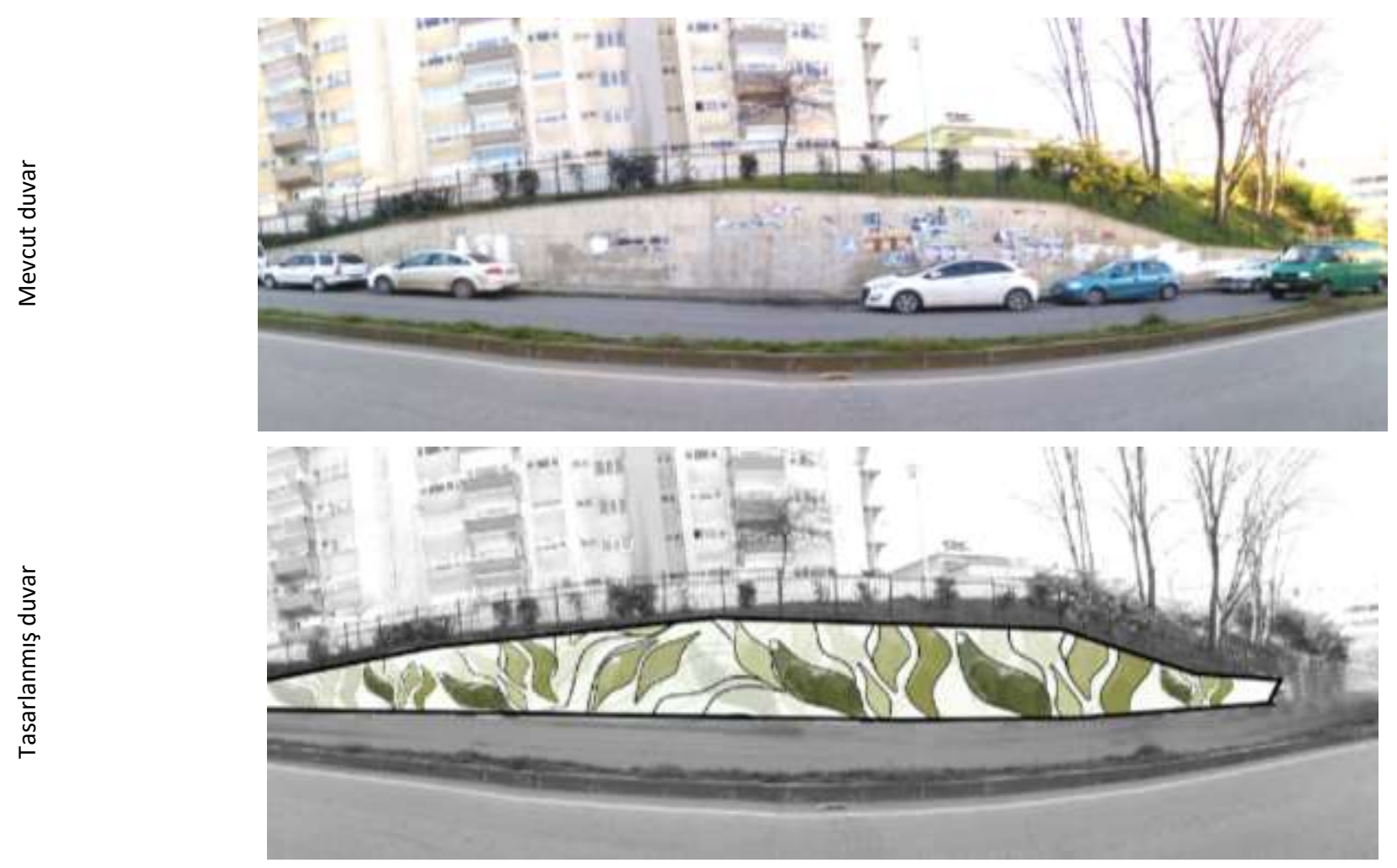

Çizelge 3'de 5 faktör ve her bir değişkenin faktörler altındaki ağırlıkları verilmiştir. Bu sonuçlara bakıldığında 1. faktör grubu altındaki ifadelerin diğer gruplar altındaki ifadelerden daha önemli olduğunu görebilmekteyiz. Bu faktör altındaki en büyük yükü "hatırlanabilirdir" parametresi almıştır (.882). "uyumludur" (.808)", "algılanabilirdir" (.790)", "dinlendiricidir" (.736) ve "süreklidir" (.686) parametreleri ise diğer yüksek yüklü parametreler arasındadır. Sonuçlara baktığımızda ise gruplandırmalar arasında, fonksiyonel parametreler ve 
bitkisel parametrelerin daha yüksek faktör yüklerine sahip olduğu görülmektedir. Tüm faktör yükleri arasında en yüksek oranı alan "hatırlanabilir" (.882) parametresi ile 1. faktörü grubunu temsil etmektedir. Bu faktör yükü 1. Parametre altındaki diğer yüksek yüklü parametreler (uyumludur, algılanabilirdir, dinlendiricidir, sürekli) ile yakından ilişkili ve önceliklidir. Bu sonuçlara göre faktör Çizelge 5. Parametrelerin faktör analizi sonuçları sınıflarını adlandırdığımızda 1. faktör grubuna "hatırlanabilir", 2. faktör grubuna "özgün", 3. faktör grubuna "güzel", 4. faktör grubuna "işlevsel", 5. faktör grubuna "bütünlük" diyebiliriz. Bu parametrelerin peyzaj değeri açısından önemli ve birbirleri ile ilişkili olduğu bulunmuştur (Çizelge 5).

\begin{tabular}{|c|c|c|c|c|c|c|}
\hline & \multirow{2}{*}{ DEĞiŞKENLER } & \multicolumn{5}{|c|}{ Faktör Yükleri } \\
\hline & & 1 & 2 & 3 & 4 & 5 \\
\hline \multirow{5}{*}{ 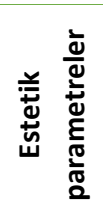 } & Yapılan bu düşey bahçe uygulaması "güzeldir" & .132 & .236 & .717 & .358 & .173 \\
\hline & Yapılan bu düşey bahçe uygulaması “özgündür” & -.123 & .769 & .220 & .130 & .434 \\
\hline & Yapılan bu düşey bahçe uygulaması "etkileyicidir" & -.569 & .637 & -.019 & -.114 & .415 \\
\hline & Yapılan bu düşey bahçe uygulaması "algılanabilirdir" & .790 & -.155 & .124 & .243 & .112 \\
\hline & Yapılan bu düşey bahçe uygulaması "okunaklıdır" & .621 & -.428 & .493 & .248 & .032 \\
\hline \multirow{6}{*}{ 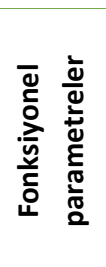 } & Yapılan bu düşey bahçe uygulaması "işlevseldir" & -.043 & .323 & -.339 & .710 & -.302 \\
\hline & Yapılan bu düşey bahçe uygulaması "davetkardır" & .637 & .325 & .285 & .032 & -.278 \\
\hline & Yapılan bu düşey bahçe uygulaması "süreklidir"”" & .686 & .380 & -.200 & -.339 & -.140 \\
\hline & Yapılan bu düşey bahçe uygulaması "hatırlanabilirdir" & .882 & -.090 & -.069 & -.250 & -.100 \\
\hline & Yapılan bu düşey bahçe uygulaması "konforludur" & -.246 & -.567 & -.174 & .105 & -.006 \\
\hline & Yapılan bu düşey bahçe uygulaması "dinlendiricidir" & .736 & .064 & -.083 & -.087 & .351 \\
\hline \multirow{6}{*}{ 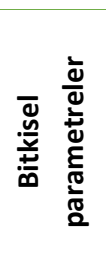 } & Yapılan bu düşey bahçe uygulaması "doğaldır" & .561 & .134 & -.565 & .149 & .299 \\
\hline & Yapılan bu düşey bahçe uygulaması "uyumludur" & .808 & .212 & -.280 & -.127 & .099 \\
\hline & Yapılan bu düşey bahçe uygulamada "bütünlük" etkisi & -.167 & -.601 & -.115 & -.339 & .524 \\
\hline & Yapılan bu düşey bahçe uygulaması "çeşitlidir" & .136 & -.171 & -.294 & .591 & .363 \\
\hline & Yapılan bu düşey bahçe uygulamasında "mahremiyet" etkisi & .047 & .324 & .363 & -.336 & .010 \\
\hline & Yapılan bu düşey bahçe uygulaması bitkisel anlamda "yeterlidir" & .188 & -.457 & .446 & .051 & .197 \\
\hline
\end{tabular}

Mevcutta bulunan duvarın "korunmalı", "yenilenmeli", "geliştirilmeli" parametreleri ve "yapılan yeni tasarımı görmek isterim" parametrenin istatistiksel olarak anlamlı olup olmadığını belirlemek için SPSS (v. 23.0) kullanılarak 'One-Sample $\mathrm{T}$ ' testi uygulanmıştır. Test sonuçlarına bakıldığında "Yeni yapılan duvarı "görmek" isterim" parametresi ve "Mevcuttaki duvarın durumu "yenilenmeli"” parametreleri istatiksel olarak anlamlı çıkan parametrelerdir $(p<0.01)$ (Çizelge 6).

Çizelge 6. One sample T-test sonuçları

\begin{tabular}{|c|c|c|c|c|}
\hline & $\mathrm{t}$ & df & $\begin{array}{c}\text { Std. } \\
\text { Deviation }\end{array}$ & $\begin{array}{c}\text { Mean } \\
\text { Difference }\end{array}$ \\
\hline Mevcuttaki duvarın durumu "korunmalı" & 29.807 & 99 & 1.07021 & 3.19000 \\
\hline Mevcuttaki duvarın durumu "yenilenmeli" & 42.302 & 99 & .84393 & 3.57000 \\
\hline Mevcuttaki duvarın durumu "geliştirilmeli" & 41.765 & 99 & .90028 & 3.76000 \\
\hline Yeni yapılan duvarı "görmek" isterim & 69.741 & 99 & .65528 & 4.57000 \\
\hline
\end{tabular}

Çalışmanın bir diğer istatistiksel aşamasında, çalışmanın öğrencilere ve eğitime olan katkısı sorgulanmıştır. "ekolojik bir yaklaşım ile tasarladığınız bu tasarımın size farkındalık yarattığını düşünüyor musunuz?" ve "ileride düşey bahçe tasarlamak ister misiniz?" sorularına \%81 ve
\%90 oranla "evet" cevabı alınmıştır. "Dersten önce düşey bahçe uygulama isteğiniz var mıydı?" Sorusuna \%51 oranla "hayır" cevabı alınmıştır. Çalışmadan sonra bu cevabın olumluya dönmüş olması yapılan çalışmanın öğrencilere katkı sağladığını bizlere göstermektedir. 
Alınan bir diğer olumlu sonuç ise "dersteki bu tasarım aşamasının sizler için faydalı olduğunu düşünüyor musunuz?" sorusuna verilen $\% 67$ oranla "evet" cevabıdır. Katılımcılar için "yerinde gözlem yaparak problemli bir duvara karar verip tasarlamanın sizler için faydalı olduğunu düşünüyor musunuz?" sorusuna \%46 oranla evet cevabı alınmıştır. Aynı zamanda katılımcılar \%76 oranla "ileride böyle çalışmalara katılmak ister misiniz?" sorusuna evet cevabı alınmıştır (Çizelge 7).

Çizelge 7. Çalışmanın öğrencilere ve eğitime katkısının sorgulanması

\begin{tabular}{|c|c|c|c|c|c|c|c|c|c|}
\hline \multirow{2}{*}{ Değişkenler } & \multicolumn{2}{|c|}{ Evet } & \multicolumn{2}{|c|}{ Hayır } & \multicolumn{2}{|c|}{ Kısmen } & \multicolumn{2}{|c|}{ Fikrim yok } & \multirow{2}{*}{$\begin{array}{r}\text { Toplan } \\
100\end{array}$} \\
\hline & $\%$ & $f$ & $\%$ & & $\%$ & $f$ & $\%$ & $f$ & \\
\hline $\begin{array}{l}\text { Ekolojik bir yaklaşım ile tasarladığınız bu tasarımın size } \\
\text { farkındalık yarattığını düşünüyor musunuz? }\end{array}$ & 81 & 81 & 8 & 8 & 11 & 11 & - & - & 100 \\
\hline İleride düşey bahçe tasarlamak ister misiniz? & 90 & 90 & 5 & 5 & - & - & 5 & 55 & 100 \\
\hline $\begin{array}{l}\text { Bu dersten önce düşey bahçe uygulama isteğiniz var } \\
\text { mıydı? }\end{array}$ & 42 & 42 & 51 & 51 & 7 & 7 & - & - & 100 \\
\hline $\begin{array}{l}\text { Dersteki bu tasarım aşamasının sizler için faydalı } \\
\text { olduğunu düşünüyor musunuz? }\end{array}$ & 67 & 67 & 23 & 23 & - & - & 10 & 10 & 100 \\
\hline $\begin{array}{l}\text { Yerinde gözlem yaparak problemli bir duvara karar } \\
\text { verip tasarlamanın sizler için faydalı olduğunu } \\
\text { düşünüyor musunuz? }\end{array}$ & 46 & 46 & 34 & 34 & 12 & 12 & 8 & 8 & 100 \\
\hline İleride böyle çalışmalara katılmak ister misiniz? & 76 & 76 & 3 & 3 & 11 & 11 & 10 & 10 & 100 \\
\hline
\end{tabular}

Öğrencilerin tasarladığı düşey bahçe ve peyzaj değeri arasındaki ilişkiyi belirlemek için korelasyon analizi yapılmıştır. Sonuçta parametreler arasındaki korelasyon analizi ile ilişki durumları belirlenmiştir. Pearson korelasyon katsayıları \%99 önem düzeyinde hesaplanmıştır (Çizelge 8). Analiz sonucunda peyzaj parametreleri arasında yer alan "süreklilik" ile beklenti düzeyi ölçüm parametrelerinden olan "uyumlu" parametresi arasında en yüksek korelasyon tespit edilmiştir $\left(r=.747^{* *}\right)$. Yine peyzaj değeri parametreler arasında yer alan "algılanabilir" ile "okunaklı" parametresi arasında korelasyon tespit edilmiştir ( $\left.r=.711^{* *}\right)$. Üçüncü sırada yüksek oranlı korelasyon "özgün" ve "etkileyici" parametreleri arasında görülmüştür ( $\left.r=.697^{* *}\right)$. Korelasyon sonuçlarına bakıldığında en yüksek korelasyon "fonksiyonel parametreler" ve "bitkisel parametreler" arasındadır (uyumlu ve süreklilik $r=.747^{* *}$ ). Tüm verilere ait korelasyon bilgileri Çizelge 8'de verilmiştir

Çizelge 8. Etkinlikten beklentilerin ve etkinliğin eğitime katkısı arasındaki ilişkileri gösteren korelasyon çizelgesi

\begin{tabular}{|c|c|c|c|c|c|c|c|c|c|c|c|c|c|c|c|c|c|}
\hline & A & B & C & D & $E$ & $\mathrm{~F}$ & G & $\mathrm{H}$ & 1 & J & $\mathrm{K}$ & $\mathrm{L}$ & $M$ & $\mathrm{~N}$ & 0 & $\mathrm{P}$ & $\mathrm{R}$ \\
\hline$A$ & 1 & & & & & & & & & & & & & & & & \\
\hline B & .402 & 1 & & & & & & & & & & & & & & & \\
\hline C & .089 & $.697 * *$ & 1 & & & & & & & & & & & & & & \\
\hline D & .181 & .101 & .502 & 1 & & & & & & & & & & & & & \\
\hline$E$ & .408 & .255 & .641 & $.711 * * *$ & 1 & & & & & & & & & & & & \\
\hline $\mathrm{F}$ & .310 & .174 & .280 & .395 & .309 & 1 & & & & & & & & & & & \\
\hline G & .034 & .017 & -.137 & .229 & .021 & .542 & 1 & & & & & & & & & & \\
\hline $\mathrm{H}$ & .088 & .193 & .553 & .633 & .474 & .518 &. .686 & 1 & & & & & & & & & \\
\hline 1 & .105 & .365 & .171 & .203 & .046 & .337 & .338 & .109 & 1 & & & & & & & & \\
\hline J & .042 & .021 & .233 & .544 & .442 & .322 & .420 & .627 & .190 & 1 & & & & & & & \\
\hline $\mathrm{K}$ & .101 & .051 & .099 & .415 & .090 & .081 & .490 & .423 & .097 & .543 & 1 & & & & & & \\
\hline $\mathrm{L}$ & .043 & .038 & .278 & .522 & $.219 *$ & .483 & $.747 * * *$ & .665 & .319 & .543 & .611 & 1 & & & & & \\
\hline$M$ & .108 & .176 & .196 & .031 & .051 & .069 & .091 & .053 & -.169 & .172 & .101 & .011 & 1 & & & & \\
\hline $\mathrm{N}$ & .053 & .015 & .124 & .187 & .105 & -.019 & -.120 & -.001 & .063 & .129 & .233 & .151 & .235 & 1 & & & \\
\hline $\mathrm{O}$ & .232 & .292 & .064 & -.06 & -.156 & .381 & .258 & -.095 & .231 & .020 & -.075 & .104 & .228 & .090 & 1 & & \\
\hline $\mathrm{P}$ & .234 & .097 & .034 & .170 & .413 & .014 & .042 & .204 & .080 & .079 & .248 & .016 & .010 & .116 & .219 & 1 & \\
\hline $\mathrm{R}$ & .011 & .192 & .289 & .008 & .003 & .046 & .029 & .151 & .097 & .018 & -.094 & .006 & .130 & .259 & .478 & .238 & 1 \\
\hline
\end{tabular}

${ }^{*}(p<0.05),{ }^{* *}(p<0.01)$, Estetik parametreler; A- Güzeldir , B- Özgündür, C- Etkileyici, D- Algllanabilir, E- Okunakl, Fonksiyonel parametreler ; F- Davetkâr, GSüreklilik, H- Harılanabilir, I- Konforlu, J- Dinlendirici, K- Doğal, Bitkisel parametreler; L- Uyumlu, M- Bütün, N- Cesitli, O- Mahremiyet, P- Yeterli, R- İ̧levsel 


\section{SONUÇ}

Bu çalışmada, mühendislik bilgisi dersi kapsamında düşey bahçe tasarlatılmış ve ortaya çıkan ürünlerin peyzaj değeri açısından önemi incelenmiştir. Çalışma sonucunda tasarlanan duvarların peyzaj değeri açısından önemi, eğitime katkısı ve ekolojik kaygılar ile yapılan tasarımların eğitim sürecindeki önemi vurgulanmıştır. Elde edilen sonuçlar Çizelge 1-2-3-4-5-6-7-8' de verilmiştir. Bu bağlamda 2018-2019 bahar dönemi içerisinde "mühendislik bilgisi" dersi kapsamında tasarlanan ürünleri değerlendirdiğimizde aşağıdaki sonuçlara ulaşmak mümkündür;

- Tasarım alternatiflerine uygulanan faktör analizi sonuçlarında fonksiyonel parametreler ve bitkisel parametrelerin diğer parametrelere oranla daha yüksek faktör yüklerine sahip olduğu görülmüştür. Aynı zamanda en yüksek sonucu alan "hatırlanabilir" parametresi uyumlu (.808), algılanabilir (.790), dinlendirici (.736) ve sürekli (.686) parametreleri ile ilişkili olduğu alınan sonuçlar arasındadır. Bu sonuç yapılacak olan düşey bahçe uygulamalarında bu parametrelere önceliğin verilmesi gerektiğini ve aralarındaki olumlu ilişkinin göz ardı edilmemesi gerektiğini bununla birlikte düşey bahçe tasarımında, fonksiyonel ve bitkisel parametrelerin peyzaj değeri açısından daha önemli olduğu göstermektedir (Çizelge 5). Aynı zamanda katılımcı grup olan öğrencilerin tasarımlarını yaparken fonksiyonel ve bitkisel parametrelere önem verdiğini göstermektedir.

- Yapılan bu çalışmanın öğrenciler üzerinde "farkındalık yaratmış (\%81)" ve "yerinde gözlem yaparak problemli bir duvarı tasarlamanın faydalı olduğunu düşünmeleri (\%46)" yapılan bu çalışmanın amacına ulaştığını göstermektedir. Öğrencilerin dersten sonra düşey bahçe tasarlama isteklerin artmış olması ise çalışmanın eğitime katkı sağlamış olduğunu gösteren bir diğer sonuçtur. Illeride düşey bahçe tasarlamak ister misiniz? sorusuna alınan \%90 evet cevabı ise öğrencilerin bu konuya dair ilgilerini ve farkındalık seviyelerini arttırdığını göstermektedir (Çizelge 7).

- Korelasyon çizelgesinde fonksiyonel ve bitkisel parametreler arasında bir ilişkinin olduğu görülmektedir (Çizelge 8). Bu sonuç öğrencilerin, tasarladıkları ürünleri yaparken fonksiyonel ve bitkisel dokuyu bir arada düşündüklerini göstermektedir.

Sonuç olarak, çalışma kapsamında uygulanan bu yöntemin dersin "amacına" daha çok katkı sağladığı söylenebilir. Aynı zamanda çalışmanın öncesi ve sonrasını kapsayan soru ve istatistikler ile hedeflenen amaçlara ulaşıldığı görülmüştür. Öğrencilerin farkındalık seviyelerinin arttırıldığı ve eğitimlerine katkı sağladığı da yapılan bu çalışmanın katkıları arasındadır.

\section{KAYNAKLAR}

Bekar M, Güneroğlu N, (2016) Utilization of Living Walls in Urban Ecosystems", in: Enviromenthal Sustainability and Landscape Management, Efe R, Cürebal i, Gaf A, Toth B, Eds., St. Kliment Ohridski University Press, SOFIA, 467-482.

Coma J, Pérez G, de Gracia A, Burés S, Urrestaraz, M, Cabeza L F (2017). Vertical greenery systems for energy savings in buildings: $A$ comparative study between green walls and green facades. Building and environment, 111: 228-237.

Green Roof Organization (2008) Introduction to Green Walls Technology, Benefits \& Design. Jacobs, Green Plants for Green Buildings

Güleç Özer D, Turan B O (2015) Ecological Architectural Design Education Practices Via Case Studies. Megaron 10(2):113-129

Hepcan Ç C, Hepcan Ş (2018) Kentsel yeşil altyapı analizi: Bornova örneği. Mediterranean Agricultural Sciences, 31(1): 37-43

Korol E, Shushunova N, Rerikh S (2019). New green roof and green wall systems for implementation in the coverings. In E3S Web of Conferences. EDP Sciences. 97(06023).

Ragheb A, El-Shimy H, Ragheb G. (2016). Green architecture: A concept of sustainability. Procedia-Social and Behavioral Sciences, 216: 778-787

Timur Ö B, Karaca E (2013) Vertical gardens. In Advances in Landscape Architecture. IntechOpen.

Ünal U, Akyüz D E (2018) Yeşil Altyapı Uygulamaları Kapsamında Yağmur Hendeklerinin Önemi ve Sürdürülebilir Kent Anlayışı ile Değerlendirilmesi, İklim Değişikliği ve Çevre, 3(2): 55-63

Yüksel N (2013) Dikey Bahçe Uygulamalarının Yurtdışı ve İstanbul Örnekleri İle İrdelenmesi, Yüksek Lisans Tezi, Bahçeşehir Üniversitesi, İstanbul. 